\title{
Root-knot nematode disease of chickpea in Nepal
}

(Keywords: Meloidogyne spp., Cicer arietinum, survey)

\author{
S. B. SHARMAT, R. P. SAH‡, ONKAR SINGH† and H. A. VAN RHEENEN†
}

fInternational Crops Research Institute for the Semi-Arid Tropics (ICRISAT), Patancheru, A.P. 502 324, India fNational Grain Legumes Improvement Program, Rampur, Dist Chitwan, Nepal

Abstract. The root-knot nematode disease of chickpea caused by Meloidogyne spp. was found to be widespread in the tarai region of Nepal. The disease was moderate to severe in Bhairahawa, Gadari, Gopalkoti, and Rampur. In Nawaipur, Nepalganj and Parwanipur, the disease incidence was low. Leucas aspera, a common weed in chickpea fields, was found to harbour the root-knot nematode.

Root-knot nematode disease, caused by Meloidogyne spp., appears to be one of the most important nematode diseases of chickpea (Cicer arietinum L.) in Nepal (Manandhar and Amatya, 1987) as it is in many countries (Sharma, 1988). We observed that chickpeas were very severely damaged by this disease at the research farm of the National Grain Legumes Improvement Programme, Rampur, Nepal. In some portions of the farm the crop died due to the severity of the disease. As chickpea is one of the most important grain legumes in Nepal, we undertook a preliminary survey of some of the major chickpeaproducing areas in the tarai region to assess the distribution and severity of the disease. Survey trips were undertaken in March 1988 when the crop was in the podding stage. The surveys covered chickpea-growing regions between Nepalganj (mid-west) and Hardinath (mid-east), and chickpea crops in farmers' fields adjacent to roadsides and at the research farms were examined. The distance between survey sites was variable and more fields were observed in regions where chickpeas were cultivated extensively. Five to 10 plants were gently uprooted from each field, and the roots were carefully observed for root-knots (galls) caused by Meloidogyne spp. The incidence of root galling or root-knots was scored on a 1 to 9 scale (Table 1). Above-ground symptoms were also noticed at different locations. Areas covered and survey routes are given in Figure 1.

The root-knot disease was observed in many farmers' fields, as well as at different research stations in seven districts (Table 1). Above-ground symptoms varied from one location to another. In the sandy soils of Bhairahawa, Gadari, Gopalkoti, and Rampur, crop growth was poor and plants were stunted. In a farmer's field in Gadari, where the disease was very severe, more than $50 \%$ loss in yield was expected, whereas in Hardinath plant growth was, in general, good despite the presence of more than 50 galls

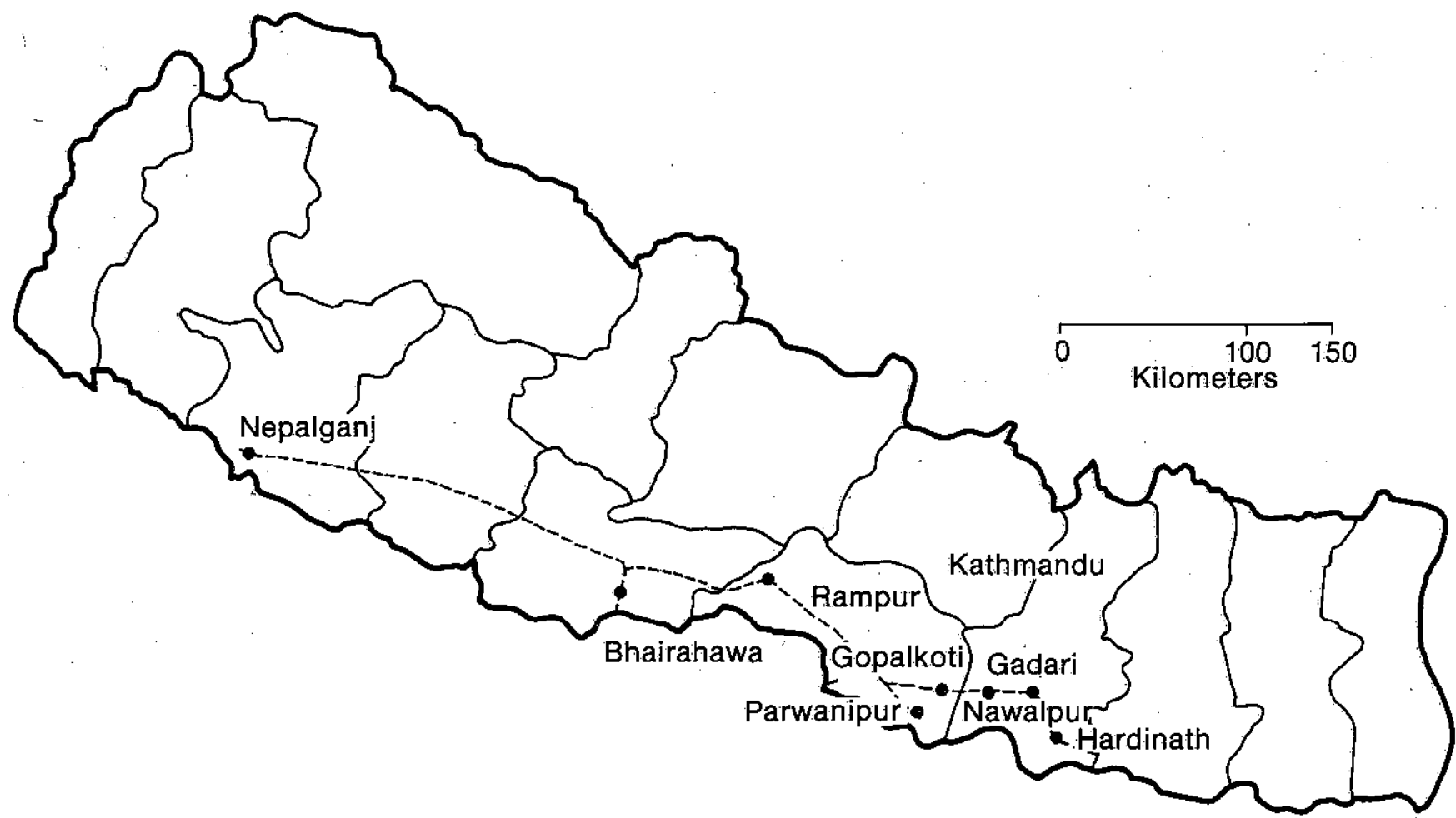

Figure 1. Survey of root-knot disease of chickpea in Nepal-the route followed 
Table 1 Root-knot disease of chickpea in different regions in Nepal

\begin{tabular}{llc}
\hline Location & District & $\begin{array}{c}\text { Root galling } \\
\text { scale and range }\end{array}$ \\
\hline Bhairahawa & Rupandehi & $5-7$ \\
Gadari & Sarlahi & $5-9$ \\
Gopalkoti & Rautahat & $3-7$ \\
Hardinath & Dhanusha & $3-7$ \\
Nawalpur & Sarlahi & $1-3$ \\
Nepalganj & Banke & $1-3$ \\
Parwanipur & Bara & $1-3$ \\
Rampur & Chitwan & $5-9$ \\
\hline
\end{tabular}

$1=$ no root galls; $3=1$ to 10 galls per plant; $5=11$ to 30 galls; $7=31$ to 100 galls; $9=$ more than 100 galls. (The score indicates the range observed in different fields in each region.)

on the root system and loss in yield was expectedly very low. In Nepalganj the crop was very good and plants were free from this disease at the research station, while one to 10 root galls per plant were observed in farmers' fields.

The root-knot disease is widespread in Nepal and we strongly suspect that it is responsible for significant losses in yield in many regions, particularly in those with sandy soils. Chickpea is sown in winter after rice and maize crops, when temperatures vary from $10^{\circ} \mathrm{C}$ to $25^{\circ} \mathrm{C}$. These crops are not good hosts of the root-knot nematode species Meloidogyne incognita and $M$. javanica, which are reported to attack chickpea in the Indian subcontinent (Sharma, 1985). The nematode might be reproducing on weed hosts during rainy and post-rainy seasons as severe infection of this nematode occurred on Leucas aspera Spreng, a common weed in farms in Nepal.

The results of this preliminary survey show that there is an urgent need to initiate intensive surveys of chickpea for nematode diseases to estimate their economic importance in the country.

\section{Acknowledgement}

This work was submitted as JA No. 866 by the lnternational Crops Research Institute for the Semi-Arid Tropics (ICRISTAT).

\section{References}

MANANDHAR, H. K. and AMATYA, P., 1987. Plant parasitic nematodes in Nepal. International Nematology Network News. letter, 4, 30-34.

SHARMA, S. B., 1985. A world list of nematodes associated with chickpea, groundnut, pearl millet, pigeonpea, and sorghum. Pulse Pathology. Progress Report No. 42. Patancheru, A.P. 502324 (India: International Crops Research Institute for the Semi-Arid Tropics).

SHARMA, S. B., 1988. Nematode diseases of groundnut, pigeonpea, chickpea, sorghum, and pearl millet. Legumes Pathology Progress Report 1. Patancheru, A.P. 502 324, (India: International Crops Research Institute for the Semi-Arid Tropics). 